\title{
Pulmonary Hypertension in Chronic Hemodialysis Patients at Aristide Le Dantec University Hospital
}

\author{
Maria Faye $^{1^{*}}$, Ahmed Tall Lemrabott ${ }^{1}$, Niakhaleen Keita ${ }^{1}$, Moustapha Faye ${ }^{1,2}$, Romina Ghassani ${ }^{1}$, \\ Mansour Mbengue ${ }^{2,3}$, Bacary Ba ${ }^{1}$, Seynabou Diagne ${ }^{1}$, Abdou Niang ${ }^{2,3}$, El Hadj Fary Ka ${ }^{1,2}$ \\ ${ }^{1}$ Nephrology Department, Aristide Le Dantec University Hospital, Dakar, Senegal \\ ${ }^{2}$ Cheikh Anta Diop University, Dakar, Senegal \\ ${ }^{3}$ Nephrology Department, Dalal Jamm Hospital, Dakar, Senegal \\ Email: *mariafye@hotmail.com
}

How to cite this paper: Faye, M., Lemrabott, A.T., Keita, N., Faye, Mo., Ghassani, R., Mbengue, M., Ba, B., Diagne, S., Niang, A. and Ka, E.H.F. (2022) Pulmonary Hypertension in Chronic Hemodialysis Patients at Aristide Le Dantec University Hospital. Open Journal of Nephrology, 12, 93-100. https://doi.org/10.4236/ojneph.2022.121009

Received: February 1, 2022

Accepted: February 27, 2022

Published: March 2, 2022

Copyright $\odot 2022$ by author(s) and Scientific Research Publishing Inc. This work is licensed under the Creative Commons Attribution International License (CC BY 4.0).

http://creativecommons.org/licenses/by/4.0/

\begin{abstract}
Introduction: Pulmonary hypertension $(\mathrm{PH})$ is defined as high blood pressure in the lungs. It is recently described as a vascular disease entity in chronic kidney disease, particularly for chronic hemodialysis patients. The aims of this study were to determine the prevalence of $\mathrm{PH}$, to describe clinico-biological and morphological characteristics and to identify risk factors associated with $\mathrm{PH}$ in hemodialysis patients. Patients and methods: This is a cross-sectional, descriptive, and analytical study during a period of 8 months from January 1 , 2019, to August 31, 2019, in the hemodialysis center of nephrology department of Aristide Le Dantec Hospital. All chronic hemodialysis patients for more than 3 months and with PH confirmed by cardiac doppler ultrasound were included. Results: During the study period, 25/94 patients on chronic hemodialysis, presented with pulmonary hypertension (26.6\%). The mean age was $49.3 \pm 12.9$ years. The sex ratio $(\mathrm{M} / \mathrm{F})$ was 0.92 . Exertional dyspnea was found in 18 patients $(72 \%)$. Cardiac auscultation revealed an arrhythmia in 3 patients (12\%), augmented second heart sound in 12 patients (48\%). On transthoracic doppler ultrasound, pulmonary systolic arterial pressure was on average $51.4 \pm 13.2 \mathrm{mmHg}$. $\mathrm{PH}$ was moderate in 13 patients (52\%), mild in 9 patients (36\%) and severe in 3 patients (12\%). The left ventricular ejection fraction was altered in 9 patients (36\%). Three patients (12\%) had valve calcifications. They were mainly located at aortic valve $(8 \%)$ and mitral valve (4\%). The major risk factors associated to $\mathrm{PH}$ in our patients are pathological fractures $(p=0.023)$, aortic calcifications $(p=0.023)$, ischemic heart disease $(\mathrm{p}=0.023)$. The duration of hemodialysis represents another favoring factor $(\mathrm{p}=0.042)$. Also implicated are arrhythmias $(\mathrm{p}=0.004)$, high cardiac index $(\mathrm{p}=0.043)$, ventricular dilatation $(\mathrm{p}=0.034)$ and left atrial dilation $(\mathrm{p}=$
\end{abstract}


$0.015)$, as well as dilation of the inferior vena cava $(\mathrm{p}=0.048)$.

\section{Keywords}

Pulmonary Hypertension, Chronic Hemodialysis Patients, Transthoracic Doppler Ultrasound, Dakar

\section{Introduction}

Pulmonary hypertension $(\mathrm{PH})$ is defined by elevation of systolic pulmonary arterial pressure above $35 \mathrm{~mm} \mathrm{Hg}$ measured by transthoracic Doppler ultrasound. It is characterized by an increase in pulmonary vascular resistance which can lead to right ventricular failure [1]. Primary $\mathrm{PH}$, whose mechanisms are incompletely known, is a vascular disease entity recently described in chronic kidney disease, for chronic hemodialysis patients. It corresponds to the 5th subtype of WSPH classification (World Symposium of Pulmonary Hypertension) established in 2008 at Dana Point [2] and updated in 2013 at Nice [3]. Primary pulmonary hypertension is a major problem for hemodialysis patients due to its high prevalence, sometimes reaching 68\% [4] [5] [6] [7], and its significant morbidity and mortality [8]. The mechanisms are multifactorial and appear to be due to a combination of pre and post capillary mechanisms [9]. The factors often incriminated are represented by advanced age, duration on hemodialysis, volume overload, anemia, arteriovenous fistula, low left ventricular ejection fraction, left heart anomalies, valvular calcifications [10] [11]. Due to the high prevalence of $\mathrm{PH}$ in chronic hemodialysis patients, it is necessary to screen for this disorder and minimize its effects. Data from the Maghreb show a prevalence ranging from $10 \%$ to $16 \%$ in Morocco [11] [12] and 26.3\% in Tunisia [13]. To our knowledge, in sub-Saharan Africa, in Senegal in particular, no data on PH in chronic hemodialysis patients by cardiac doppler ultrasound is available. Based on this observation, we conducted this study to determine the prevalence of $\mathrm{PH}$ in chronic hemodialysis patients, to describe the clinico-biological and morphological characteristics of these patients and to identify the factors associated with the occurrence of this $\mathrm{PH}$.

\section{Patients and Methods}

This is a cross-sectional, descriptive, and analytical study over a period of 8 months from January 1, 2019, to August 31, 2019, in the hemodialysis center of the nephrology department of Aristide Le Dantec Hospital. All patients on chronic hemodialysis for more than 3 months and with $\mathrm{PH}$ confirmed by cardiac doppler ultrasound were included. Patients with $\mathrm{PH}$ before start hemodialysis and those who dialysed temporaly in our center were excluded. Epidemiological data (age, gender, marital status, socio-professional status) hemodialysis parameters (type of vascular access, seniority in hemodialysis, duration and number 
of sessions, dry weight and inter-dialytic weight gain), clinical and paraclinical data were studied. The data was collected from the patients' medical files, using an exploitation sheet. All included patients provided written free and informed consent. Transthoracic doppler ultrasound was performed by a cardiologist using an ultrasound scanner equipped with pulsed, continuous and color doppler. The measurements were performed in accordance with the recommendations of the American Society of Echocardiography [14], on patients in the dorsal and left lateral decubitus position, in inter-dialytic period. The diagnostic of pulmonary arterial hypertension was according to 2015 ESC/ERS Guidelines for the diagnosis and treatment of pulmonary hypertension [1].

\section{Statistical Analysis}

The data collected was then entered into an Epi-info7 database. For the descriptive study, the quantitative parameters of the patients are expressed as mean \pm standard deviation and the qualitative parameters are expressed in number and frequency. The analytical study was made with cross tables. To compare the frequencies, we used Pearson's Khi2 tests or Fischer's two-sided exact test depending on their conditions of applicability with a significance level for a $p \leq 0.05$. To find the risk factors associated with $\mathrm{PH}$, the comparison was made between two groups of hemodialysis patients: those with $\mathrm{PH}$ and those without $\mathrm{PH}$.

\section{Results}

During the study period, 25/94 patients on chronic hemodialysis, had pulmonary arterial hypertension, with a hospital prevalence of $26.6 \%$. The mean age was $49.3 \pm 12.9$ years [ 24 and 81 years]. The sex ratio was 0.92 , with a slight female predominance (52\%). The initial nephropathy was hypertensive nephropathy in 9 patients (36\%), it was an undetermined cause in 6 patients (24\%) and chronic glomerulonephritis in 5 patients $(20 \%)$. The mean duration on hemodialysis was $75 \pm 40.9$ months (Table 1 ). The vascular access was an arteriovenous fistula in 20 patients (80\%). Exertional dyspnea was found in 18 patients (72\%). Cardiac auscultation revealed an arrhythmia in 3 patients (12\%), augmented second heart sound in 12 patients (48\%). The other clinical manifestations were dominated by bone pain in 18 patients (72\%). Paraclinically, 23 patients were anemic (92\%) with a mean hemoglobin value of $8.38 \pm 1.89 \mathrm{~g} / \mathrm{dl}$. Hypocalcemia was present in 6 patients $(24 \%)$ and hyperphosphatemia in only one case (4\%). Secondary hyperparathyroidism was observed in 20 patients (95.2\%). The mean PTHi was $1166 \pm 604 \mathrm{ng} / \mathrm{l}$. Mean vitamin D was $28.8 \pm 9.1$ $\mathrm{ng} / \mathrm{l}$ (Table 2). A vitamin D deficiency was found in half of the cases $(50 \%)$. The $\mathrm{Kt} / \mathrm{V}$ averaged $1.45 \pm 0.28$. It was insufficient in 9 patients (34.8\%). On electrocardiogram, left ventricular hypertrophy was found in 8 patients $(57.1 \%)$, left atrial hypertrophy in 5 patients $(35.7 \%)$ and repolarization disorders in 3 patients (21.4\%). There was 1 case (7.5\%) of conduction disorders, arrhythmias, and right ventricular hypertrophy (Table 3). On transthoracic Doppler ultrasound, 
Table 1. Clinical and dialytic baseline.

\begin{tabular}{lc}
\hline \multicolumn{1}{c}{ Parameters } & Results \\
\hline $\begin{array}{l}\text { Epidemiological data } \\
\text { Prevalence }\end{array}$ & $26.6 \%$ \\
$\quad$ Mean age & $49.3 \pm 12.9$ years \\
\hline Gender & \\
$\quad$ Female & $\mathrm{n}=13(52 \%)$ \\
Male & $\mathrm{n}=12(48 \%)$ \\
\hline Initial Nephropathies & \\
Hypertensive nephropathy & $\mathrm{n}=09(36 \%)$ \\
Renal polycystosis & $\mathrm{n}=02(08 \%)$ \\
Chronic Glomerulonephritis (CGN) & $\mathrm{n}=03(12 \%)$ \\
Chronic tubulo-interstitial nephropathies (CTIN) & $\mathrm{n}=03(12 \%)$ \\
Diabetic nephropathy & $\mathrm{n}=02(08 \%)$ \\
Non-specified & $\mathrm{n}=06(24 \%)$ \\
\hline Dialysis data & \\
Mean duration & $75 \pm 40.9 \mathrm{month}$ \\
Interdialytic weigh gain & $2.08 \pm 0.94 \mathrm{~kg}$ \\
KT/V & $1.45 \pm 0.28$ \\
\hline
\end{tabular}

Table 2. Biological baseline of patients.

\begin{tabular}{cc}
\hline Parameters & Mean \\
\hline Hemoglobin $(\mathrm{g} / \mathrm{dl})$ & $8.38 \pm 1.89$ \\
Ferritinemia $(\mu \mathrm{g} / \mathrm{l})$ & $695.8 \pm 299$ \\
Albuminemia $(\mathrm{g} / \mathrm{l})$ & $30.9 \pm 8.1$ \\
Calcemia $(\mathrm{mg} / \mathrm{l})$ & $88.8 \pm 7.1$ \\
Phosphatemia $(\mathrm{mg} / \mathrm{l})$ & $31 \pm 11.4$ \\
PTH $(\mathrm{pg} / \mathrm{ml})$ & $1166 \pm 604$ \\
Vitamin D $(\mathrm{ng} / \mathrm{l})$ & $28.8 \pm 9.1$ \\
\hline
\end{tabular}

Table 3. Electrocardigraphic characteristics of patients.

\begin{tabular}{cc}
\hline Results & N (\%) \\
\hline Left ventricular hypertrophy & $08(57.1)$ \\
Left atrial hypertrophy & $05(35.7)$ \\
Sub-epicardial ischemia & $01(7.1)$ \\
Rhythm disorder & $01(7.1)$ \\
Right ventricular hypertrophy & $01(7.1)$ \\
Atrio-ventricular block & $05(1.54)$ \\
\hline
\end{tabular}

the mean systolic pulmonary arterial pressure was $51.4 \pm 13.2 \mathrm{mmHg}$ with extremes of 35 and $87 \mathrm{mmHg}$. $\mathrm{PH}$ was moderate in 13 patients (52\%), mild in 9 patients (36\%) and severe in 3 patients (12\%). The left ventricular ejection frac- 
tion was on average $57.6 \pm 13.1 \%$, it was altered in 9 patients $(36 \%)$. Three patients $(12 \%)$ had valve calcifications. They were mainly located at the aortic valve $(8 \%)$ and at the mitral valve (4\%). The major risk factors associated of $\mathrm{PH}$ in our patients are pathological fractures $(\mathrm{p}=0.023)$, aortic calcifications $(\mathrm{p}=0.023)$, ischemic heart disease $(p=0.023)$. The duration of hemodialysis represents another favoring factor $(\mathrm{p}=0.042)$. Also involved are arrhythmias $(\mathrm{p}=0.004)$, high cardiac index $(p=0.043)$, ventricular $(p=0.034)$ and left atrial $(p=0.015)$ dilation, as well as dilation of the inferior vena cava $(\mathrm{p}=0.048)$ (Table 4).

\section{Discussion}

The reported prevalence of $\mathrm{PH}$ in the literature in hemodialysis patients was $26 \%-40 \%$, detected by Doppler ultrasound [15] [16]. In our series, the hospital prevalence of $\mathrm{PH}$ in hemodialysis patients was $26.6 \%$. This hospital frequency was higher than that found by Ezziani in Morocco which was 10\% [12]. Amor in Tunisia also found a frequency of $26.3 \%$. [13]. In Iran, Miri found a prevalence of $22 \%$ [17]. And in the USA, Navaneethan found a higher prevalence than that of our series, $30 \%$ - 40\% [18]. The frequency of $\mathrm{PH}$ in chronic hemodialysis patients in our study was similar to the Tunisian and Iranian study and significantly lower than that carried out in the USA. This could be explained by the different dialysis protocols and the low sampling of African and Middle Eastern studies; compared to the American series whose cohort included 625 cases of PH out of a total of 2959 hemodialysis patients [18]. The sex ratio found in our study was 0.92 . This slight female predominance was similar to that found in Morocco, which was 0.94 [19]. The mean age of our patients was $49.3 \pm 12.9$ years. Ait Faqih e in Morocco found a mean age similar (46 \pm 16 years) [19]. In the series of Shen in China, and Fadaii in Iran, the mean ages were respectively $62.3 \pm 12.9$ years, $63 \pm 16$ years, [20] [21]. The data in the literature generally agree and find a higher proportion of elderly people on chronic hemodialysis presenting with PH. In our study, the mean PTHi level was $1165.9 \pm 604.3 \mathrm{pg} / \mathrm{ml}$

Table 4. Risk factors associated to PAH.

\begin{tabular}{cc}
\hline Parameters & P value \\
\hline Pathological fractures & 0.023 \\
Aortic calcifications & 0.023 \\
Ischemic heart disease & 0.023 \\
Arrhythmia & 0.004 \\
High cardiac index & 0.043 \\
Ventricular dilation & 0.034 \\
Left atrial dilatation & 0.015 \\
Inferior vena cava dilatation & 0.048 \\
Duration on hemodialysis & 0.042 \\
\hline
\end{tabular}


with 95.2\% secondary hyperparathyroidism. Ait Faqih found a mean PTHi level of $513 \pm 34 \mathrm{pg} / \mathrm{ml}$ [19]. Yoo found an average level of $370 \mathrm{pg} / \mathrm{ml}$ with extremes [22]. Shen found a level of $270.8 \pm 193.1 \mathrm{pg} / \mathrm{ml}$ [20]. All these results were relatively lower than in our series. This could be explained by the non-availability and the cost of curative treatments reducing the $\mathrm{PPTH}$ such as calcimimetics and by the absence of a dietician for the prevention of hyperparathyroidism. On transthoracic Doppler ultrasound, the average diameter of the left atrium in our study was $39.6 \pm 7.4 \mathrm{~mm}$ with $58.8 \%$ of cases presenting with dilation of the left atrium. Shen and Yoo found respective averages of $41.2 \pm 7.2 \mathrm{~mm}$ and $46 \pm 5.3$ $\mathrm{mm}$ [20] [22]. According to their studies, dilation of the left atrium was increased in patients with $\mathrm{PH}$ compared to patients who did not. Our data were consistent with those in the literature suggesting that $\mathrm{PH}$ was associated with an increase of dilation of the left atrium. In our series, the mean systolic diameter of the left ventricle was $33.7 \pm 9 \mathrm{~mm}$, increased in $38.9 \%$ of cases. In the Chinese and Brazilian series the values were respectively $33.2 \pm 7.5 \mathrm{~mm}$ and $32 \pm 8 \mathrm{~mm}$ [22] [23]. In our study, the left ventricular ejection fraction (LVEF) averaged $57.6 \%$. The fraction was altered in $36 \%$ of cases. According to Ait Faqih and Fadai, it was respectively $56.3 \% \pm 9.4 \%$ and $56 \% \pm 5 \%$, similar to our study [6]. In Shen's and Yoo's series, the mean LVEF was respectively $66 \%$ and $72 \% \pm 13$, relatively higher than in our series [20] [22]. We did not find any correlation between LVEF and PH. The results of the Maghreb and China series agree with ours. However, the Iranian and Brazilian series [21] [22] agree to associate an altered LVEF with the development of PH. Indeed, it has been proven that most patients with $\mathrm{PH}$ on chronic hemodialysis originate from left heart failure [24]. Our results could be explained by the small sampling of our cohort. In our study, valvular calcifications accounted for $12 \%(\mathrm{n}=3)$ of cases. According to Ait Faqih, there was $33.3 \%$ valve calcification [19]. In our series, among patients with moderate PH, $22.2 \%$ had aortic calcification and this result was statistically significant. In Ait Faqih's serie, the association was demonstrated between valvular calcification and the development of $\mathrm{PH}$ [19]. Our data are consistent with those of the literature [19]. The inferior vena cava was dilated in $28.6 \%$ of cases. There was a statistically significant difference between $\mathrm{PH}$ severity and inferior vena cava dilation. Indeed, this is associated with a volume overload in chronic hemodialysis patients and when no measures are taken, these patients subsequently develop left ventricular hypertrophy resulting in the appearance of $\mathrm{PH}$.

The main limitation of this study was the small sample size.

\section{Conclusion}

This study shows the relatively high prevalence of pulmonary hypertension in chronic hemodialysis patients at Aristide Le Dantec University Hospital. Risk factors of $\mathrm{PH}$ in this population were clearly identified. These risk factors are mainly cardiac, hence the importance of regular cardiological monitoring for chronic hemodialysis patients. 


\section{Conflicts of Interest}

The authors declare no conflicts of interest regarding the publication of this paper.

\section{References}

[1] Galie, N., Humbert, M., Vachieryc, J.L., Gibbs, S., Lang, I., Torbicki, A., et al. (2015) 2015 ESC/ERS Guidelines for the Diagnosis and Treatment of Pulmonary Hypertension. Kardiologia Polska, 73, 1127-1206. https://doi.org/10.5603/KP.2015.0242

[2] Simonneau, G., Robbins, I.M., Beghetti, M., et al. (2009) Updated Clinical Classification of Pulmonary Hypertension. Journal of the American College of Cardiology, 54, S43-S54. https://doi.org/10.1016/j.jacc.2009.04.012

[3] Simonneau, G., Gatzoulis, M.A., Adatia, I., et al. (2003) Updated Clinical Classification of Pulmonary Hypertension. Journal of the American College of Cardiology, 62, 34-41. https://doi.org/10.1016/j.jacc.2013.10.029

[4] Agarwal, R. (2012) Prevalence, Determinants and Prognosis of Pulmonary Hypertension among Hemodialysis Patients. Nephrology Dialysis Transplantation, 27, 3908-3914. https://doi.org/10.1093/ndt/gfr661

[5] Fabbian, F., Cantelli, S., Molino, C., et al. (2010) Pulmonary Hypertension in Dialysis Patients: A Cross-Sectional Italian Study. International Journal of Nephrology, 11, 463-475.

[6] Kumbar, L., Fein, P.A., Rafiq, M.A., et al. (2007) Pulmonary Hypertension in Peritoneal Dialysis Patients. Advances in Peritoneal Dialysis, 23, 127-131.

[7] Unal, A., Sipahioglu, M., Oguz, F., et al. (2009) Pulmonary Hypertension in Peritoneal Dialysis Patients: Prevalence and Risk Factors. Peritoneal Dialysis International, 29, 191-198. https://doi.org/10.1177/089686080902900214

[8] Li, Z., Liu, S., Liang, X., et al. (2014) Pulmonary Hypertension as an Independent Predictor of Cardiovascular Mortality and Events in Hemodialysis Patients. International Urology and Nephrology, 46, 141-149. https://doi.org/10.1007/s11255-013-0486-Z

[9] Subbiah, R., Bakhshi, A., Brian, O., et al. (2012) Prevalence and Mechanism of Pulmonary Hypertension in Chronic Hemodialysis by Invasive Measurements. JACC, 59, 1618. https://doi.org/10.1016/S0735-1097(12)61619-2

[10] Abassi, Z., Nakhoul, F., Khankin, E., et al. (2006) Pulmonary Hypertension in Chronic Dialysis Patients with Arteriovenous Fistula: Pathogenesis and Therapeutic Prospective. Current Opinion in Nephrology and Hypertension, 15, 353-360. https://doi.org/10.1097/01.mnh.0000232874.27846.37

[11] Abelhad, M., Kasongo, A., Nassiri, I., et al. (2015) Prevalence of Pulmonary Hypertension in Patients Undergoing Hemodialysis. Archives of Cardiovascular Diseases Supplements, 7, 216. https://doi.org/10.1016/S1878-6480(15)30228-7

[12] Ezziani, M., Najdi, A., Mikou, S., et al. (2014) Anomalies échocardiographiques chez l'hémodialysé chronique: Prévalence et facteur de risque. The Pan African Medical Journal, 18, Article No. 216. https://doi.org/10.11604/pamj.2014.18.216.4438

[13] Amor, S., Zellama, D., Safa, N., et al. (2015) Description des anomalies écho-cardiographiques retrouvées chez les patients en hémodialyse chronique. Néphrologie \& Thérapeutique, 11, 287-337. https://doi.org/10.1016/j.nephro.2015.07.077

[14] Roberto, M.L., Luigi, P., Mor-Avi, V., et al. (2015) Recommendations for Cardiac Chamber Quantification by Echocardiography in Adults: An Update from the Amer- 
ican Society of Echocardiography and the European Association of Cardiovascular Imaging. European Heart Journal-Cardiovascular Imaging, 16, 233-271. https://doi.org/10.1093/ehjci/jev014

[15] Delgado, J.F., Conde, E., Sanchez, V., et al. (2005) Pulmonary Vascular Remodeling in Pulmonary Hypertension Due to Chronic Heart Failure. European Journal of Heart Failure, 7, 1011-1016. https://doi.org/10.1016/j.ejheart.2004.10.021

[16] Morrell, N., Adnot, S., Archer, S., et al. (2009) Cellular and Molecular Basis of Pulmonary Arterial Hypertension. Journal of the American College of Cardiology, 54, S20-S31. https://doi.org/10.1016/j.jacc.2009.04.018

[17] Miri, M., Hejazi, S., Maghsoudlou, F., et al. (2018) Prevalence of Pulmonary Hypertension in End-Stage Renal Disease Patients Undergoing Hemodialysis and Peritoneal Dialysis at a Referral Center in Mashhad. Iranian Journal of Kidney Diseases, 12, 364-368.

[18] Navaneethan, D.S., Roy, J., Tao, K., et al. (2016) Prevalence, Predictors, and Outcomes of Pulmonary Hypertension in CKD. Journal of the American Society of Nephrology, 27, 877-886. https://doi.org/10.1681/ASN.2014111111

[19] Ait Faqih, S., Noto-Kadou-Kaza, B., Abouamrane, L.M., et al. (2016) Pulmonary Hypertension: Prevalence and Risk Factors. International Journal of Cardiology: Heart \& Vasculature, 11, 87-89. https://doi.org/10.1016/j.ijcha.2016.05.012

[20] Shen, S. and Sun, Q. (2015) Analysis of Clinically Relevant Factors for Pulmonary Hypertension in Maintenance Hemodialysis Patients. Medical Science Monitor, 21, 4050-4056. https://doi.org/10.12659/MSM.895279

[21] Fadaii, A., Koohi-Kamali, H., Bagheri, B., et al. (2013) Prevalence of Pulmonary Hypertension in Patients Undergoing Hemodialysis. Iranian Journal of Kidney Diseases, 7, 60-63.

[22] Hyung Bok Yoo, H., dos Reis, R., Moneda Telini, W., et al. (2017) Association of Pulmonary Hypertension with Inflammation and Fluid Overload in Hemodialysis Patients. Iranian Journal of Kidney Diseases, 11, 303-308.

[23] Li, Z., Liang, X., Liu, S., et al. (2014) Pulmonary Hypertension: Epidemiology in Different CKD Stages and Its Association with Cardiovascular Morbidity. PLoS ONE, 9, e114392. https://doi.org/10.1371/journal.pone.0114392

[24] Pabst, S., Hammerstingl, C., Hundt, F., et al. (2012) Pulmonary Hypertension in Patients with Chronic Kidney Disease on Dialysis and without Dialysis: Results of the PEPPER-Study. PLoS ONE, 7, e35310.

https://doi.org/10.1371/journal.pone.0035310 